\title{
Demographic factors determining folic acid supplementation in pregnant and childbearing age women
}

\author{
Grażyna Kurzawińska', 2 , Justyna Magiełda ${ }^{1}$, Anna Romała ${ }^{1}$, Joanna Bartkowiak-Wieczorek² \\ Magdalena Barlik ${ }^{1,2}$, Krzysztof Drews ${ }^{1,2}$, Marcin Ożarowski ${ }^{4,5}$, \\ Agnieszka Seremak-Mrozikiewicz ${ }^{1,2}$ \\ ${ }^{1}$ Division of Perinatology and Women's Diseases, Poznan University of Medical Sciences, Poznan, Poland \\ ${ }^{2}$ Laboratory of Molecular Biology, Division of Perinatology and Women's Diseases, Poznan University of Medical Sciences, \\ Poznan, Poland \\ ${ }^{3}$ Laboratory of Experimental Pharmacogenetics, Department of Clinical Pharmacy and Biopharmacy, University of Medical Sci- \\ ences, Poznan, Poland \\ ${ }^{4}$ Department of Pharmacology and Phytochemistry, Institute of Natural Fibers and Medicinal Plants, Poznan, Poland \\ ${ }^{5}$ Department of Pharmaceutical Botany and Plant Biotechnology, Poznan University of Medical Sciences, Poznan, Poland
}

\begin{abstract}
Objectives: Adequate folate intake constitutes a significant problem in the periconceptional period and early pregnancy but can be achieved by folic acid (FA) supplementation. Low intake of folate may cause numerous negative effects on the pregnancy outcome, including recurrent miscarriage, preeclampsia, fetal hypotrophy, premature delivery, premature placental abruption, and intrauterine fetal death. The aim of the study was to evaluate factors determining FA supplementation in the population of Polish women before and during pregnancy.

Material and methods: The study group consisted of 257 women hospitalized postpartum at the Division of Perinatology and Women's Diseases, Poznan University of Medical Sciences, Poland. We evaluated folic acid intake considering selected demographic data. A structured questionnaire was used to evaluate folic acid intake before and during pregnancy of the investigated women.

Results: The vast majority of the investigated women (89.1\%) took FA during pregnancy. During the pre-pregnancy period, a statistically significantly higher supplementation of folic acid was observed among women with the monthly income level of $>5000$ PLN $(p=0.03)$, and among women who planned their pregnancy as compared to women who did not plan their pregnancy $(p<0.001)$. During pregnancy, these differences disappeared. A statistically significantly higher number of secundi- and multiparas did not take FA during pregnancy as compared to primiparas $(p=0.008)$. No correlation between cigarette smoking and FA intake was observed.

Conclusions: Our analysis showed that FA intake increased (by 36.2\%) during pregnancy as compared to the pre-pregnancy period, and depended on income, parity, and pregnancy planning.
\end{abstract}

Key words: folate, folic acid (FA), pregnancy, supplementation, demographic factors

Ginekologia Polska 2018; 89, 4: 211-216

\section{INTRODUCTION}

Pregnancy is associated with higher demand for nutritional compounds due to physiological changes occurring in the body of the woman and demands of the fetus. Proper amount of vitamins and minerals, as well as adequate caloric intake, are extremely important in this period and lead to proper weight gain and adequate fetal development. On the contrary, poor level of minerals and vitamins might significantly negatively affect the fetus. Thus, it is vital to supplement the diet of a pregnant woman especially with folate, 
iron, vitamin $\mathrm{D}$, iodine and polyunsaturated fatty acids in order to prevent maternal and fetal complications [1-3].

Folic acid (FA), chemically pteroylglutamic acid, belongs to $B$-group vitamins and consists of three elements: pteridine (2-amino-4 hydroxy-6-methylpteridine), p-aminobenzoic acid (PABA), and glutamine acid. FA is synthesized by some plants, bacteria, and yeast. It regulates growth, division and cell function, preserving genetic material, and contributes to methylation processes in numerous reactions in the human body. It improves psychological health and nervous system function, prevents anemia and development of several cancers, as well as plays an important role in proper liver, stomach and intestine function $[4,5]$.

Intake of appropriate dosage of folate in the periconceptional period and early pregnancy remains a significant problem. Proper folate level in pregnant women is achieved by FA supplementation during the periconceptional period and daily administration during pregnancy. In Poland, daily recommended doses of FA in pregnant and breastfeeding women range between $400-800 \mu \mathrm{g}$ and $450-530 \mu \mathrm{g}$, respectively. Since the 60 's of the twentieth century, studies have shown that regular FA supplementation decreases the risk of neural tube defects in families affected by this complication. Observational and randomized studies from the last forty years confirmed the significant role of FA supplementation in decreasing birth defects (neural tube defects, orofacial cleft, hearts defects, and Down syndrome) [6]. Numerous studies have reported that women with insufficient folate intake in the periconceptional period and first weeks of pregnancy are at an increased risk of giving birth to infants with neural tube defects, although the exact mechanism responsible for this effect remains unclear [7-9]. Low intake of folate could also have many negative effects on pregnancy outcome, including recurrent miscarriage, preeclampsia, fetal hypotrophy, premature delivery, premature placental abruption, and intrauterine fetal death $[10,2,11]$.

Taking into consideration the necessity of preserving adequate level of folate in women of childbearing age, and additionally the augmentation of folate demand in pregnant women, FA supplementation seems to be the appropriate preventive measure to improve pregnancy outcome. Therefore, food fortification with FA was started in several countries such as the United States, Canada, Chile, and Australia, where a significant decrease in the incidence of fetal neural tube defects was observed [12]. In Poland, the Prevention of Primordial Neural Tube Defects Program has been realized since 1997. It was designed to promote FA supplementation in women of childbearing potential and raise awareness about the possibility of preventing neural tube defects among the general public. National Health Programs, developed during 2004-2013 and 2007-2015, advertise the necessity to prevent neural tube defects [13]. However, there is still a need for further research on the intake of FA by women of childbearing age, as it would allow to assess the frequency of neural tube defects in the context of active prevention. Additionally, the multiplicity of factors affecting the awareness of women and conditioning adequate FA supplementation before and during pregnancy remains an interesting issue.

The aim of our study was to evaluate demographic factors which determine FA supplementation in the population of Polish women before and during pregnancy.

\section{MATERIAL AND METHODS Patients}

A total of 320 women hospitalized postpartum at the Division of Perinatology and Women's Diseases, Poznan University of Medical Sciences, Poland, were recruited for the study. Out of them, 43 failed to complete the interview and 20 refused to participate after the initial agreement, so they were disqualified from the study. In the end, the study group consisted of 257 women. The investigation was conducted between January 2014 and December 2014. All participants were informed about the goal of the study and gave their written consent. Local Ethics Committee approved of the study design. All women had singleton pregnancies. Subjects with nervous system diseases, psychiatric and cognitive complications were excluded from the study. Women with several obstetric pathologies (preeclampsia, fetal hypotrophy, stillbirths, recurrent miscarriage, preterm delivery), as well as women who delivered a defected child also were disqualified.

\section{Questionnaire}

A structured questionnaire was used to evaluate folic acid intake before and during pregnancy of the investigated women. The interview was completed between $48-72$ hours postpartum. The questionnaire consisted of 30 questions divided into categories: demographic data, clinical data, perinatal care, dietary habits, use of drugs and supplements. The following demographic data were collected: age, family status (married, widow, divorced, domestic partnership, single), area of residence (urban, rural), level of education (primary, vocational, secondary, bachelor's and master's degrees), and monthly income (<2000 PLN, 2000-5000 PLN, > 5000 PLN). Components of perinatal care included wanted or unwanted pregnancy, parity, gestational age at delivery, beginning of perinatal care, total number of prenatal visits. Dietary habits and drugs included questions about type of diet and smoking (before and during pregnancy). Each patient was questioned about the use of folic acid in detail.

\section{Statistical analyses}

All statistical analysis were performed with $\mathrm{R}$ software (version 3.4.3), at the 5\% significance level. T-test was used in case of parametric variables (age, weight), Wilcoxon test was used for education. Chi square test or Fisher exact test 
(used whenever expected cell value was $<5$ ) was used to analyze the association between categorical variables.

\section{RESULTS \\ Characteristics of the study participants}

Mean age of the 257 participants was 31.0 years (range: $18-42$ years, $9.7 \%$ between $18-25$ years, $75.9 \%$ between $26-35$ years, and $14.4 \%$ over 35 years of age). The $55.3 \%$, of the studied population were residents of urban areas, while $44.7 \%$ lived in rural areas. All participants had formal education: master's degree (69.3\%), bachelor's degree (3.9\%), secondary (19.8\%), vocational (5.1\%), and primary (1.9\%). As far as marital status is concerned, most of the investigated women were married $(82.9 \%)$, with the remaining $11.3 \%$ were unmarried but living with a partner, $4.3 \%$ were single, $1.5 \%$ were divorced, there were no widows in the studied groups. $84,0 \%$ of qualified women has planned their pregnancy. Most of the patients in our study were mothers of one child (149 patients $58.0 \%$ ), while 108 (42.0\%) patients had 2 or more children (median 1 range 1-5). A monthly household income of $<2000$ PLN, between 2000-5000 PLN, and > 5000 PLN was declared by 34.2\%, 54.5\% and $11.3 \%$ of the respondents, respectively. A normal diet was reported by $84.1 \%$ of the women, whereas vegetarian and meat predominated diet declared the same amount (1.9\% each) of participants. Smoking before and during pregnancy was reported by $18.3 \%$ and $5.5 \%$ of the patients, respectively. Mean weight gain in pregnancy was about $14 \mathrm{~kg}$. All data is presented in Table 1.

\section{Relationship between demographic parameters and folic acid supplementation}

Our analysis showed that 136 women (52.9\%) were taking folic acid before pregnancy at a dose of $0.4-0.8 \mathrm{mg}$, while 121 women (47.1\%) did not supplement their diet with folic acid at all. During pregnancy, most of the investigated women (89.1\%) were taking FA. There were no observed age differences between the groups of takers and non-takers of $F A(p=0.98)$. Compared to the pre-pregnancy period, the intake of FA increased by $36.2 \%$ during pregnancy. During pregnancy, 9 women in study group $(9 / 257,3.5 \%)$ took FA at an increased dose of $5.0 \mathrm{mg}$ because of having the previous child with neural tube defects ( 2 women) and recurrent miscarriages in anamnesis (7 women).

Any statistical differences between the groups of takers and non-takers of FA connected to area of residence, educational level, marital status, maternal body weight, maternal diet, smoking status as well as folic acid intake before and during pregnancy have been observed.

Our analysis showed that most of women who did not take folic acid during pregnancy had a monthly income of below 2.000 PLN. In the group with high monthly income (> 5000 PLN), more women were taking FA before
Table 1. Background characteristics of participants $(n=257)$

\begin{tabular}{|c|c|}
\hline Characteristics & \\
\hline $\begin{array}{l}\text { Maternal age (years), mean } \pm S D \\
\text { Height }[\mathrm{cm}] \text {, mean } \pm S D \\
\text { Weight before pregnancy }[\mathrm{kg}] \text {, mean } \pm S D \\
\text { Weight during pregnancy }[\mathrm{kg}] \text {, mean } \pm S D \\
\text { Number of children, median (range) }\end{array}$ & $\begin{array}{c}31.0 \pm 4.4 \\
166.6 \pm 11.0 \\
61.9 \pm 11.0 \\
75.9 \pm 12.5 \\
1(1-5)\end{array}$ \\
\hline $\begin{array}{l}\text { Maternal age groups, } n(\%) \\
18-25 \text { years } \\
26-35 \text { years } \\
>35 \text { years }\end{array}$ & $\begin{array}{c}25(9.7) \\
195(75.9) \\
37(14.4)\end{array}$ \\
\hline $\begin{array}{l}\text { Area of residence, } n(\%) \\
\text { urban } \\
\text { rural }\end{array}$ & $\begin{array}{l}142(55.3) \\
115(44.7)\end{array}$ \\
\hline $\begin{array}{l}\text { Educational level, } \mathrm{n}(\%) \\
\text { primary } \\
\text { vocational } \\
\text { secondary } \\
\text { bachelor's degree } \\
\text { master's degree }\end{array}$ & $\begin{array}{c}5(1.9) \\
13(5.1) \\
51(19.8) \\
10(3.9) \\
178(69.3)\end{array}$ \\
\hline $\begin{array}{l}\text { Marital status, } \mathrm{n}(\%) \\
\text { widowed } \\
\text { divorced } \\
\text { married } \\
\text { living with partner } \\
\text { single }\end{array}$ & $\begin{array}{c}0(0.0) \\
4(1.5) \\
213(82.9) \\
29(11.3) \\
11(4.3)\end{array}$ \\
\hline $\begin{array}{l}\text { Planning of pregnancy, } n(\%) \\
\text { Planned pregnancy } \\
\text { Unplanned pregnancy }\end{array}$ & $\begin{array}{l}216(84.0) \\
41(16.0)\end{array}$ \\
\hline $\begin{array}{l}\text { Household income (PLN), } \mathrm{n}(\%) \\
\quad<2000 \\
2000-5000 \\
>5000\end{array}$ & $\begin{array}{c}88(34.2) \\
140(54.5) \\
29(11.3)\end{array}$ \\
\hline $\begin{array}{l}\text { Diet, } \mathrm{n}(\%) \\
\text { vegetarian } \\
\text { meat predominance } \\
\text { standard } \\
\text { other }\end{array}$ & $\begin{array}{c}5(1.9) \\
5(1.9) \\
216(84.1) \\
31(12.1)\end{array}$ \\
\hline $\begin{array}{l}\text { Folic acid intake, } n(\%) \\
\text { before pregnancy (yes/no) } \\
\text { during pregnancy (yes/no) }\end{array}$ & $\begin{array}{c}136(52.9) / 121(47.1) \\
229(89.1) / 28(10.9)\end{array}$ \\
\hline $\begin{array}{l}\text { Smoking, } n(\%) \\
\text { before pregnancy (yes/no) } \\
\text { during pregnancy (yes/no) }\end{array}$ & $\begin{array}{c}47(18.3) / 210(81.7) \\
14(5.5) / 243(94.5)\end{array}$ \\
\hline
\end{tabular}

pregnancy as compared to the lower-income group ( $<2000$ PLN/month). The difference was statistically significant $(p=0.03)$. However, this difference disappeared during pregnancy because most women in both groups (with high and low income) took FA supplementation.

The clear majority $(89.1 \%, 229 / 257)$ of women accepted FA intake during pregnancy. Interestingly, a statistically significantly lower FA consumption was found among secundi-and multiparous as compared to primiparous women ( $p=0.008$ ).

In next step we assessed the consumption of folic acid during pregnancy among Polish postpartum women and analyzed the difference of folic acid supplementation between planned and unplanned pregnancies. As might be 
expected, a statistically significantly higher percentage of FA supplementation before pregnancy was observed among women who planned their pregnancy than among those whose pregnancy was not planned $(p<0.001)$. In the planned pregnancy group $8.2 \%(n=21)$ of women reported not taking folic acid during pregnancy, and in the unplanned pregnancy group only $2.7 \%$ of women $(n=7)$.

Relationship between statistically significant demographic parameters of folic acid takers and non-takers, before and during pregnancy is showed in Figure 1 and on Table 2.
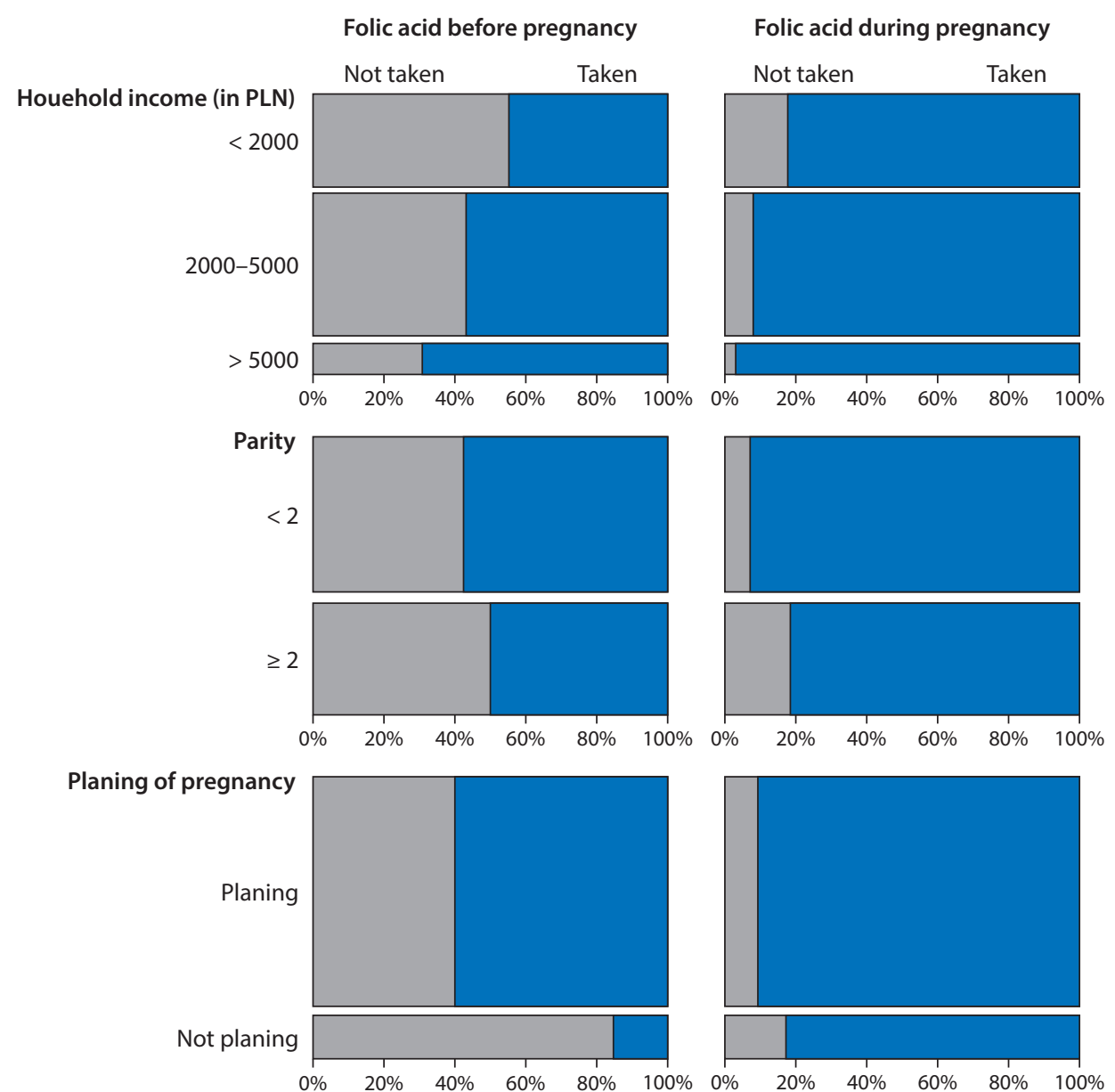

Figure 1. Relationship between demographic parameters (household income, parity, and pregnancy planning) of folic acid takers and non-takers, before and during pregnancy

Table 2. The frequency distribution of the variables concerning the relationship between demographic parameters and folic acid dose

\begin{tabular}{|c|c|c|c|c|c|c|c|}
\hline \multirow{2}{*}{ Dose } & & \multicolumn{3}{|c|}{ FA supplementation before pregnancy } & \multicolumn{3}{|c|}{ FA supplementation during pregnancy } \\
\hline & & Not taken & $0.4-0.8 \mathrm{mg}$ & $5.0 \mathrm{mg}$ & Not taken & $0.4-0.8 \mathrm{mg}$ & $5.0 \mathrm{mg}$ \\
\hline \multirow{4}{*}{$\begin{array}{l}\text { Household income (in PLN) } \\
n=257\end{array}$} & $<2000$ & $50(19.5)$ & $38(14.8)$ & $0(0.00)$ & $15(5.8)$ & $70(27.2)$ & $3(1.2)$ \\
\hline & $2000-5000$ & $62(24.1)$ & $78(30.3)$ & $0(0.00)$ & $12(4.7)$ & $124(48.3)$ & $4(1.5)$ \\
\hline & $>5000$ & $9(3.5)$ & $20(7.8)$ & $0(0.00)$ & $1(0.4)$ & $26(10.1)$ & $2(0.8)$ \\
\hline & \multicolumn{4}{|c|}{$p=0.03$} & \multicolumn{3}{|c|}{$p=0.12$} \\
\hline \multirow{3}{*}{$\begin{array}{l}\text { Parity } \\
n=257\end{array}$} & $<2$ & $66(25.7)$ & $83(32.3)$ & $0(0.00)$ & $9(3.5)$ & $133(51.7)$ & $7(2.7)$ \\
\hline & $\geq 2$ & 55 (21.4) & $53(20.6)$ & $0(0.00)$ & $19(7.4)$ & 75 (33.9) & $2(0.8)$ \\
\hline & \multicolumn{4}{|c|}{$p=0.31$} & \multicolumn{3}{|c|}{$p=0.008$} \\
\hline \multirow{3}{*}{$\begin{array}{l}\text { Planning of pregnancy } \\
n=257\end{array}$} & Planned & $87(33.9)$ & $130(50.6)$ & $0(0.00)$ & $21(8.2)$ & $190(73.9)$ & $6(2.3)$ \\
\hline & Unplanned & $34(13.2)$ & $6(2.3)$ & $0(0.00)$ & $7(2.7)$ & 30 (11.7) & $3(1.2)$ \\
\hline & \multicolumn{4}{|c|}{$p<0.001$} & \multicolumn{3}{|c|}{$p=0.08$} \\
\hline
\end{tabular}




\section{DISCUSSION}

In pregnancy, much attention is paid to sufficient folate supplementation due to the fact that daily diet does not provide adequate amounts of folate as well as the level of stored folate is rapidly reduced. On the other hand, the importance of folate and choline supplementation is unquestionable as its substances play a significant role in prevention of many obstetrical complications especially neural tube defects and Down syndrome [14-16]. Additionally, assumption of Developmental Origins of Health and Disease (DOHaD) hypothesis was shown that folate has large influence on public health [17-19]. Consider the above mentioned many countries decided to initiate FA fortification programs and simultaneously recommended the folate intake before and during pregnancy [20].

Lack of reliable information about nutritional habits as well as differences in nutrient intake in women of childbearing age and during pregnancy have been observed worldwide. Also, research correlating lifestyle, socioeconomic, demographic and dietary factors with dietary supplements are very poor.

One of the first studies concerning the FA reception has shown that only $7.5 \%$ of women started supplementation at least four weeks prior to conception or pregnancy. Additionally, it reported that FA was taken by only $52.2 \%$ of pregnant women. All of these women had at least secondary education [21]. In our research $52.9 \%$ women were taking FA before pregnancy and during pregnancy $85.6 \%$ women were supplemented FA. In our study, most women were supplemented by the dose $0.4-0.8 \mathrm{mg} \mathrm{FA}$, only few of investigated patients were taking $5 \mathrm{mg} \mathrm{FA}$ (patients with a history of pregnancy complicated by neural tube defects in the fetus).

In our study, women aged 25-35 years constituted the largest group of pregnant subjects, while the number of women aged over 35 years exceeded the number of women aged less than 25 years by two-fold, there were no pregnant women of < 18 years of age. Compared to a study conducted by Popa et al., similar age distribution of pregnant women was reported [22].

Income was an interesting factor influencing pre-pregnancy FA supplementation. We have shown that more women were taking FA in the group with a monthly income of $>5000$ PLN compared to the lower-income groups $(p=0.029)$. Forster et al. in the study in population of Australian women, indicated that one of the important factor associated with an increased risk of poor FA intake was the low income ( $\leq \$ 30,000$ AUD, OR $=2.85$ ) [23].

There is a surprising relationship between FA intake during pregnancy and parity. Our study showed that FA intake is lower among secundi- and multiparous women as compared to primiparous $(p=0.008)$. Popa et al., observed a similar dependence, $52.6 \%$ of primi- and secundiparas were taking FA as compared to only $26.8 \%$ of multiparas [22]. Forster et al., also noted higher rates of multiparas who did not take FA as compared to primiparas (adjusted $\mathrm{OR}=1.89$ ) [23]. Their results may suggest that absence of FA supplementation does not necessarily result from lack of knowledge about its role but may be a conscious choice of the woman.

Our findings on the relationship between FA intake and pregnancy planning are consistent with studies conducted in other countries. The number of subjects who did not plan their pregnancy is significantly higher $(p=0.09)$ among women who did not take FA before pregnancy. Periconceptional FA intake was more likely to occur among Korean women who planned their pregnancy or who were aware of the protective effects of FA during pregnancy [24]. In a cross-sectional study on a sample of 400 pregnant women, Popa et al., noted that $49.9 \%$ of FA-takers wanted pregnancy, as compared to $30 \%$ of FA takers with unwanted pregnancy. Some authors observed that pregnancy planning was associated with a healthier lifestyle but there are still many women who could improve their lifestyle in connection to pregnancy.

We did not demonstrate an association between folate intake and type of diet in women before and during pregnancy. Meanwhile, the literature data suggest that long-term high consumption of vegetables leads to improved folate status and may reduce the risk of folate deficiency during pregnancy. In addition, the intake of vitamin B 12 results in improved folate status among people using a vegetarian diet [25].

In our study, most women took a dose of 0.4 $-0.8 \mathrm{mg}$ FA (before and during pregnancy). High doses of FA (>5 mg/24 hours) are recommended for women who experienced complications in previous pregnancies, i.e. with history of neural tube defects in the fetus. Additionally, we shown the greater FA intake during pregnancy as compared to the pre-pregnancy period. In a study conducted by Chatzi et al., $68 \%$ of the investigated women were taking $<5 \mathrm{mg} \mathrm{FA}$ daily, while $24 \%$ reported higher doses of FA ( $>5 \mathrm{mg} / 24$ hours), and $8 \%$ denied folic acid supplementation in early pregnancy. Doses of FA supplementation of $>5 \mathrm{mg} / 24$ hours were not associated with an additional increase in the neurodevelopmental scales. Women with daily FA intakes of $5 \mathrm{mg}$ were more likely to take one daily dose of supplemental folic acid, while women with higher intakes reported more than one daily dose [26].

Based on above-mentioned findings, it seems safe to conclude that in investigated group of Polish women FA supplementation depends on several sociodemographic factors such as household income, parity, and pregnancy planning. On the other hand, according to some authors, nutritional 
knowledge seems to be significantly associated with the intake of dietary supplements, regardless of the frequency of prenatal visits or sociodemographic characteristics [22].

\section{CONCLUSIONS}

1. FA intake increases during pregnancy as compared to the pre-pregnancy period what shown that pregnant women seem to be aware of potential complications caused by an inadequate amount of folate.

2. Women with better economic status, fewer children and those planning pregnancies are more likely to take FA supplementation.

3. No relationship between diet, age, cigarette smoking, body mass, and FA intake has been observed in the studied population of women.

4. Further studies concerning also the role of physicians and midwifes are needed in order to elucidate factors influencing the awareness about FA intake in women of childbearing age and during pregnancy.

\section{REFERENCES}

1. Obeid R, Koletzko B, Pietrzik K. Critical evaluation of lowering the recommended dietary intake of folate. Clin Nutr. 2014; 33(2): 252-259, doi: 10.1016/j.clnu.2013.12.013, indexed in Pubmed: 24503418.

2. Barua S, Kuizon S, Junaid MA. Folic acid supplementation in pregnancy and implications in health and disease. J Biomed Sci. 2014; 21: 77, doi: 10.1186/s12929-014-0077-z, indexed in Pubmed: 25135350.

3. Zerfu TA, Ayele HT. Micronutrients and pregnancy; effect of supplementation on pregnancy and pregnancy outcomes: a systematic review. Nutr J. 2013; 12: 20, doi: 10.1186/1475-2891-12-20, indexed in Pubmed: 23368953.

4. Zeng $\mathrm{R}, \mathrm{Xu} \mathrm{CH}, \mathrm{Xu} \mathrm{YN}$, et al. The effect of folate fortification on folic acid-based homocysteine-lowering intervention and stroke risk: a meta-analysis. Public Health Nutr. 2015; 18(8): 1514-1521, doi: 10.1017/S1368980014002134, indexed in Pubmed: 25323814.

5. Huhta J, Linask KK. Environmental origins of congenital heart disease: the heart-placenta connection. Semin Fetal Neonatal Med. 2013; 18(5): 245-250, doi: 10.1016/j.siny.2013.05.003, indexed in Pubmed: 23751925.

6. Wilson R, Wilson R, Audibert F, et al. Prenatal Screening, Diagnosis, and Pregnancy Management of Fetal Neural Tube Defects. Journal of Obstetrics and Gynaecology Canada. 2014; 36(10): 927-939, doi: 10.1016/s1701-2163(15)30444-8.

7. Pitkin RM. Folate and neural tube defects. Am J Clin Nutr. 2007; 85(1): 285S-288S, doi: 10.1093/ajcn/85.1.285S, indexed in Pubmed: 17209211.

8. Wilson RD, Davies G, Désilets V, et al. The Use of Folic Acid for the Prevention of Neural Tube Defects and Other Congenital Anomalies.Genetics Committee and Executive and Council of the Society of Obstetricians and Gynecologists of Canada. J Obstet Gynaecol Can. 2003; 25(11): 959-965, doi: 10.1016/s1701-2163(16)30248-1.

9. Greenberg JA, Bell SJ, Guan Y, et al. Folic Acid supplementation and pregnancy: more than just neural tube defect prevention. Rev Obstet Gynecol. 2011; 4(2): 52-59, indexed in Pubmed: 22102928.
10. Ramakrishnan U, Imhoff-Kunsch B, Martorell R. Maternal nutrition interventions to improve maternal, newborn, and child health outcomes. $\mathrm{Ne}$ stle Nutr Inst Workshop Ser. 2014; 78: 71-80, doi: 10.1159/000354942, indexed in Pubmed: 24504208.

11. Mantovani E, Filippini F, Bortolus R, et al. Folic acid supplementation and preterm birth: results from observational studies. Biomed Res Int. 2014; 2014: 481914, doi: 10.1155/2014/481914, indexed in Pubmed: 24724083.

12. De Wals $\mathrm{P}$, Tairou F, Van Allen Ml, et al. Reduction in neural-tube defects after folic acid fortification in Canada. N Engl J Med. 2007; 357(2): 135-142, doi: 10.1056/NEJMoa067103, indexed in Pubmed: 17625125.

13. Czeczot H. Folic acid in physiology and pathology. Postepy Hig Med Dosw (Online). 2008; 62: 405-419, indexed in Pubmed: 18772846.

14. Drews K, Różycka A, Barlik M, et al. Polymorphic variants of genes involved in choline pathway and the risk of intrauterine fetal death. Ginekol Pol. 2017; 88(4): 205-211, doi: 10.5603/GP.a2017.0039, indexed in Pubmed: 28509322.

15. Wang Li, Shangguan S, Xin Yu, et al. Folate deficiency disturbs hsa-let-7 $\mathrm{g}$ level through methylation regulation in neural tube defects. J Cell Mol Med. 2017; 21(12): 3244-3253, doi: 10.1111/jcmm.13228, indexed in Pubmed: 28631291.

16. Wang Li, Chang S, Wang Z, et al. Altered GNAS imprinting due to folic acid deficiency contributes to poor embryo development and may lead to neural tube defects. Oncotarget. 2017; 8(67): 110797-110810, doi: 10.18632/oncotarget.22731, indexed in Pubmed: 29340017.

17. Wojtyła A. Application of the hypothesis of Developmental Origin of Health and Diseases (DOHaD) in epidemiological studies of women at reproductive age and pregnant women in Poland. Ann Agric Environ Med. 2011; 18(2): 355-364, indexed in Pubmed: 22216813.

18. YajnikCS, Deshmukh US. Maternal nutrition, intrauterine programming and consequential risks in the offspring. Rev Endocr Metab Disord. 2008; 9(3): 203-211, doi: 10.1007/s11154-008-9087-z, indexed in Pubmed: 18661241.

19. Swanson JM, Entringer S, Buss C, et al. Developmental origins of health and disease: environmental exposures. Semin Reprod Med. 2009; 27(5): 391-402, doi: 10.1055/s-0029-1237427, indexed in Pubmed: 19711249.

20. Castillo-Lancellotti C, Tur JA, Uauy R. Impact of folic acid fortification of flour on neural tube defects: a systematic review. Public Health Nutr. 2013; 16(5): 901-911, doi: 10.1017/S1368980012003576, indexed in Pubmed: 22850218.

21. Szumska A, Mazur J. Ocena wiedzy, postaw i zachowań zdrowotnych kobiet $w$ wieku rozrodczym wobec profilaktycznego działania kwasu foliowego - doniesienie wstępne. Medycyna Wieku Rozwojowego. 1999; III(4).

22. Popa AD, Niță O, Graur Arhire LI, et al. Nutritional knowledge as a determinant of vitamin and mineral supplementation during pregnancy. BMC Public Health. 2013; 13: 1105, doi: 10.1186/1471-2458-13-1105, indexed in Pubmed: 24289203.

23. Forster DA, Wills G, Denning A, et al. The use of folic acid and other vitamins before and during pregnancy in a group of women in Melbourne, Australia. Midwifery. 2009; 25(2): 134-146, doi: 10.1016/j. midw.2007.01.019, indexed in Pubmed: 17543431.

24. Kim MH, Han JY, Cho YJ, et al. Factors associated with a positive intake of folic acid in the periconceptional period among Korean women. Public Health Nutr. 2009; 12(4): 468-471, doi: 10.1017/S1368980008002115, indexed in Pubmed: 19105859.

25. Koebnick C, Heins UA, Hoffmann I, et al. Folate status during pregnancy in women is improved by long-term high vegetable intake compared with the average western diet. J Nutr. 2001; 131(3): 733-739, doi: 10.1093/jn/131.3.733, indexed in Pubmed: 11238752.

26. Chatzi L, Papadopoulou E, Koutra K, et al. Effect of high doses of folic acid supplementation in early pregnancy on child neurodevelopment at 18 months of age: the mother-child cohort 'Rhea' study in Crete, Greece. Public Health Nutr. 2012; 15(9): 1728-1736, doi: 10.1017/S1368980012000067, indexed in Pubmed: 22314109. 